\title{
The Lactate/Albumin Ratio As A Prognostic Factor For Short Time Mortality In Critically III COVID-19 Patients
}

\section{Abdullah GOK}

Department of Anesthesiology and Reanimation, Malatya Training and Research Hospital Umut S KASAPOGLU ( $\square$ umutkasapoglu@gmail.com )

Department of Pulmonary and Critical Care Medicine

\section{Leman ACUN DELEN}

Department of Anesthesiology and Reanimation, Malatya Training and Research Hospital

\section{Ferda OZMEN}

Department of Anesthesiology and Reanimation, Malatya Training and Research Hospital

\section{Susen BANAZILI}

Department of Anesthesiology and Reanimation, Malatya Training and Research Hospital

\section{Research Article}

Keywords: COVID-19, lactate/albumin ratio, lactate, albumin, mortality, SARS-CoV-2, predictor

Posted Date: April 29th, 2021

DOl: https://doi.org/10.21203/rs.3.rs-478051/v1

License: (9) This work is licensed under a Creative Commons Attribution 4.0 International License. Read Full License 
The Lactate/Albumin Ratio As A Prognostic Factor For Short Time Mortality In Critically III COVID-19 Patients

\section{Abdullah GOK¹, Umut S KASAPOGLU2, Leman ACUN DELEN¹, Ferda OZMEN1, Susen BANAZILI1}

1 Department of Anesthesiology and Reanimation, Malatya Training and Research Hospital, Malatya, Turkey

2 Department of Pulmonary and Critical Care Medicine, Malatya Training and Research Hospital, Malatya, Turkey

Running title: The Lactate/Albumin Ratio In Critically III COVID-19 Patients

Corresponding Author: Umut S Kasapoglu, MD.

Department of Pulmonary and Critical Care Medicine, Malatya Training and Research Hospital, Yesilyurt, 44090, Malatya, Turkey

E-mail: umutkasapoglu@gmail.com

\section{Conflict of Interest statement}

The authors have stated explicitly that there are no conflicts of interest in connection with this article.

\section{Financial Disclosure statement}

None declared.

\section{Funding}

This manuscript did not receive any specific grant from funding agencies in the public, commercial, or not-for-profit sectors.

\section{Acknowledgement}

Special thanks to all the physicians, nurses and caregivers from Malatya Training and Research Hospital. 


\section{INTRODUCTION}

The novel coronavirus disease 2019 (COVID-19) caused by acute respiratory syndrome-coronavirus-2 (SARS-CoV-2) has begun to be seen at the end of 2019, in Wuhan, China. After that, World Health Organization (WHO) has declared COVID-19 pandemic, and it isn't still even close to being over.1,2 Due to the COVID-19 is associated with a high risk of mortality and morbidity in critically ill patients, lots of clinical studies have focused on the identification of prognostic factors to reduce COVID-19 associated mortality. 3,4

The level of serum lactate is the most commonly used biomarker for the management of critically ill patients in the emergency department and intensive care unit (ICU). ${ }^{5}$ Hyperlactatemia or elevated levels of serum lactate may be caused by different clinical settings including sepsis, liver diseases, shock, and cancer. Many published studies have shown the association between hyperlactatemia and poor survival of critically ill patients. ${ }^{5-7}$ Also, in a clinical study by Velavan et al., levels of blood lactate were found significantly elevated in hospitalized COVID-19 patients with severe diseases. ${ }^{8}$

Serum albumin that known as one of the major plasma proteins, is a negative acute phase reactant and has anti-oxidant properties. Many clinical statuses can lead to altered in the level of serum albumin.9,10 Especially, hypoalbuminemia is associated with poor prognosis and shorter survival time in many clinical settings such as sepsis, traumatic brain injury, decompensated heart failure, and cancer., ${ }^{9,11-13} \mathrm{Also}$, recently published studies showed that a lower level of serum albumin is frequently observed in severe and critically ill COVID-19 patients and it is associated with poor survival. ${ }^{14-17}$

Clinical studies have reported that the lactate/albumin ratio (LAR) could have been an important prognostic factor for the prediction of mortality in septic shock, heart failure, and cardiac arrest patients. Also, it was shown that an increased initial LAR level was superior to the initial level of serum lactate alone for in-hospital mortality. 10,18-22 To the best of our knowledge, the prognostic role of LAR in critically ill COVID-19 patients remains unknown. Therefore, in the present study, we aimed to evaluate the prognostic value of the LAR on the day of ICU admission in predicting 30-day mortality in critically ill COVID-19 patients, and compare with the initial level of serum lactate and albumin for the prediction of mortality. 


\section{MATERIALS AND METHODS}

\section{Study Design and Population}

This clinical study was approved by the Clinical Ethics Committee of Inonu University School of Medicine (protocol no: 2020/154). We performed a single-center retrospective and observational clinical study in a tertiary level ICU of Malatya Training and Research Hospital between April 2020 and December 2020. A total of 282 critically ill COVID-19 patients aged 18 years and older were enrolled into the study. Patients who died within the first 24 hours and transferred to the other ICU were excluded from the study.

\section{Data collection and Definitions}

We collected and analyzed the following data: all patients' demographic and clinical variables, scores on the Acute Physiology and Chronic Health Evaluation-II (APACHE-II) and Sequential Organ Failure Assessment (SOFA), laboratory variables, respiratory support type within 24 hours, invasive mechanical ventilation requirement, the use of vasoactive agent, ICU length of stay, and survival status of the patients at the end of day 30. Patients' clinical and laboratory variables that evaluated in this study were collected within the first 24 hours following the ICU admission.

The normal serum concentration of the albumin was 3.5-5.0 g/dL, and hypoalbuminemia was defined as the level of serum albumin $<3.5 \mathrm{~g} / \mathrm{dL} .{ }^{12}$ Also, hyperlactatemia was defined as the serum lactate level $>2$ $\mathrm{mmol} / \mathrm{L} .^{7}$

\section{Measurement of Outcome}

All patients were followed up during their ICU stay or until death, and we defined the short time mortality as death within 30 days after the ICU admission. All patients' mortality data were collected from the hospital medical record system.

\section{Statistical analysis}

We used SPSS (Statistical Package for Social Sciences) for Windows 22.0 software (SPSS Inc., Chicago, IL, USA) for the statistical analysis of the variables obtained from the hospital medical record system. All results were analyzed with a confidence interval level of $95 \%$ and a significance level of $P<$ 0.05. The homogeneity and distribution of the variables were assessed with using the SkewnessKurtosis. Frequencies and percentages were used for the categorical data, mean value \pm standard 
deviation was used for the parametric variables while median (min-max) values were used for the nonparametric variables. We used Chi-squared Test for the comparison of the categorical variables. The Independent Samples T Test was used for the analysis of the two independent groups' parametric variables while Mann-Whitney-U Test was used for the analysis of non-parametric variables. Pearson Correlation analysis was used for the assessment of the relationship between LAR and disease severity scoring systems. We used receiver operating characteristic (ROC) curve for determine the optimal cut off value of the LAR. We used the Kaplan-Meier method for determining the overall survival rates of the patients at day 30. And, Long-rank Test was used to compare the differences between the survival of the groups. After the univariate survival analysis, we used Cox Regression analysis for the assessment of the multivariate survival analysis.

\section{RESULTS}

\section{Baseline characteristics of the overall study population}

A total of 282 critically ill COVID-19 patients aged 18 years and older were included in the study. The mean age of the patients was $66.34 \pm 12.08$ years and $179(63.5 \%)$ of patients were male. 136 of the patients (48.2\%) was under 65 years of age. Hypertension (68.2\%), diabetes mellitus (38.3\%), and coronary artery disease (31.2\%) were the most common comorbidities. The SOFA and APACHE-II scores on ICU admission were found 4.00 (2-12) and 17.34 \pm 3.95 respectively. And, 137 (48.6\%) patients died within 30 days after the ICU admission.

\section{Comparison of the baseline clinical characteristics between survivors and non-survivors}

There were significant differences between the survivors and the non-survivors patients respectively age, gender, SOFA score, APACHE-II score, lymphocyte, NT-proBNP, LDH, urea, creatinine, ferritin, $\mathrm{CRP}$, and procalcitonin $(\mathrm{p}<0.05)$.As we expected, patients who died within 30 days had higher lactate levels (2.77 vs $1.73 \mathrm{mmol} / \mathrm{L}, p<0.001$ ), lower levels of serum albumin (2.73 vs $2.95 \mathrm{~g} / \mathrm{dL}, p<0.001$ ), and higher levels of $L A$ ratio $(0.92$ vs $0.55, p<0.001)$. Comparison of the baseline clinical and laboratory characteristics of the survivors and non-survivors are summarized in Table 1 and Table 2.

\section{Mortality prediction performance of lactate, albumin and, lactate/albumin ratio}

We performed ROC analysis for the prediction of 30-day mortality and also finding the optimal cut-off value of the LAR for determining the 30-day mortality. ROC analysis showed that LAR (AUC=0.824, $p<0.001)$ was superior to the serum albumin $(A \cup C=0.644, p<0.001)$ and lactate levels $(A \cup C=0.795$, 
$p<0.001$ ) for the prediction of 30-day mortality. Also, the optimal cut-off value of the LAR was found 0.60 (Figure 1) (Table 3).

\section{Comparison of the baseline clinical characteristics between patients with LAR $>0.60$ and pati- ents with LAR $\leq 0.60$}

After the determination of the cut-off value of the LAR, the overall study population divided into two groups as patients with LAR $>0.60$ and patients with $L A R \leq 0.60$. Statistically significant differences were found between the groups by age and gender $(p<0.001)$. And, patients with LAR $>0.60$ had higher SOFA and APACHE-II score on ICU admission ( $p<0.001)$. We found that laboratory findings of the organ dysfunction and inflammatory parameters were significantly elevated in patients with $L A R>0.60$. Also, serum level of albumin and count of lymphocytes was found significantly lower in patients with $L A R>0.60$. The use of vasoactive agents $(31.8 \%$ vs $24.6 \%, p<0.001)$ and 30 -day overall ICU mortality rates $(75.6 \%$ vs $13.1 \%, p<0.001)$ were significantly higher in patients with $L A R>0.60$. We also found that LAR on the day of ICU admission was positively correlated with ICU admission SOFA score $(r=0.335, p<0.001)$ and APACHE-II score $(r=0.298, p<0.001)$ (Figure 2). Comparison of the baseline clinical and laboratory characteristics of the patients with LAR $>0.60$ and patients with LAR $\leq 0.60$ are presented in Table 4 and Table 5.

\section{Survival analysis of the patients}

In the present study, 30-day overall mortality was found $48.6 \%$ in the overall study population. And, 30 day overall ICU mortality rates $(75.6 \%$ vs $13.1 \%$, p<0.001) were significantly higher in patients with LAR $>0.60$. Also, patients with hypoalbuminemia and hyperlactatemia had a significantly shorter survival time $(p<0.001)$ (Figure 3) (Figure 4). More importantly, we found that LAR $>0.60$ was associated with shorter survival time $(p<0.001)$ (Figure 5). Univariate survival analysis of the patients summarized in Table 6. We performed multivariate Cox regression survival analysis for the assessment of independent prognostic factors. It showed that LAR $>0.60$ was significant and independent prognostic factor for the 30 day mortality in critically ill COVID-19 patients (HR:10.615 Cl:5.673-19.865, p<0.001) (Table 7).

\section{DISCUSSION}

In the present study, we investigated the prognostic role of LAR on the day of ICU admission in critically ill COVID-19 patients. The main result of this study has shown that the LAR $>0.60$ was associated with a shorter survival time, and had a better prognostic performance for predicting 30-day mortality in critically ill COVID-19 patients. 
COVID-19 is associated with high risk of mortality and morbidity especially in hospitalized and critically ill patients. For this reason, several factors such as laboratory and clinical variables for the prediction of the disease severity and outcome has been defined in recently published clinical trials. ${ }^{15,16,23}$ Determination of these prognostic factors of the critically ill patients could help the decision of therapeutic approaches for improving the short and long-term outcome.10,12

Recently published clinical studies and meta-analysis that evaluate the prognostic factors in patients with COVID-19 reported increased level of lactate dehydrogenase (LDH), C-reactive protein (CRP), procalcitonin, D-dimer, cardiac biomarkers, and decreased lymphocyte count were associated with severe disease and increased mortality. Also, older age, male sex, comorbidity, and obesity can impact survival in patients with COVID-19.3,4,24-28 We found significant differences between the survivors and the non-survivors in terms of age, gender, lymphocyte, NT-proBNP, LDH, ferritin, CRP, and procalcitonin, as showed by recently published studies.

Hypoalbuminemia is frequently seen in COVID-19 patients and is associated with disease severity. Although the underlying mechanisms have not been clarified, severe COVID-19 that is characterized by hyperinflammation lead to endothelial damage and increased capillary permeability, and this can lead to the accumulation of albumin in the interstitium. Recently published studies demonstrated that lower level of serum albumin at admission is significantly associated with increased mortality. Also, hypoalbuminemia has been found as independent prognostic factor for mortality in COVID-19 patients. ${ }^{13,15-17,29,30}$ Consistent with previous clinical studies and meta-analysis, the present study has confirmed that hypoalbuminemia is associated with a shorter survival time $(p<0.001)$ (Figure 4). However, lower level of serum albumin (serum albumin level $<3.5 \mathrm{mg} / \mathrm{dL}$ ) has not found as an independent prognostic factor for the 30 -day mortality in critically ill COVID-19 patients $(p=0.463)$. However, the nutrition status of the patient, diseases that cause chronic inflammation, and liver diseases can affect the serum albumin levels in critically ill patients. ${ }^{19}$

In addition, several studies have reported that an increased level of blood lactate is associated with severe disease and increased risk of mortality in patients with COVID-19.8,25,31 Velavan et al., have reported that the level of blood lactate in COVID-19 pneumonia patients is higher compared with non-COVID19 pneumonia patients. ${ }^{8}$ In the recently published study by Vassiliou et al., have emphasized that initial blood lactate is an independent mortality predictor in critically ill COVID-19 patients. ${ }^{32}$ The present study has confirmed that hyperlactatemia is associated with a shorter survival time $(p<0.001)$ (Figure 3$)$. However, an increased level of blood lactate (blood lactate level $>2 \mathrm{mmol} / \mathrm{L}$ ) has not found as an indepen- 
dent prognostic factor for the 30 -day mortality in critically ill COVID-19 patients $(p=0.372)$. However, several clinical statuses including renal or hepatic dysfunction, medications, and thiamine deficiency can affect the blood lactate levels. ${ }^{10,21,22}$

Given these limitations of the single measurement of the lactate and albumin levels, several studies have focused on the mortality prediction performance of the lactate albumin ratio in different clinical settings. $10,18-22,33$

Studies that evaluate the clinical utility of LAR have shown that increased LAR is significantly associated with increased mortality and organ dysfunction in patients with sepsis and septic shock. In addition, these studies have shown that the mortality prediction performance of the LAR is superior to serum lactate level or albumin level alone in patients with sepsis and septic shock. ${ }^{10,18-20,33}$ Consistent with previous clinical studies, in the present study, ROC analysis showed that LAR (AUC $=0.824, p<0.001)$ was superior to the serum albumin $(A \cup C=0.644, p<0.001)$ and lactate levels $(A U C=0.795, p<0.001)$ for the prediction of 30-day mortality.

The clinical trial by Wang et al., have reported that increased lactate/albumin ratio correlated with APACHE-II score and $\mathrm{PaO}_{2} / \mathrm{FiO}_{2}$ ratio in patients with severe sepsis and septic shock. Also, they have emphasized that increased level of LAR on the day of ICU admission was associated with multiple-organ dysfunction syndrome and mortality in patients with severe sepsis and septic shock. ${ }^{33}$

Studies have also investigated the clinical utility of the LAR as a prognostic factor in other clinical settings.In the recently published study by Guo et al., they have emphasized that LAR can be a useful prognostic factor for the short and long-term mortality in critically ill patients with heart failure.22Kong et al. found that increased LAR was significantly associated with poor neurologic outcomes in out-of-hospital cardiac arrest patients. Also, the prognostic performance of the LAR was found superior to a single measurement of lactate for predicting neurologic outcomes and survival. ${ }^{21}$

Consistent with previous clinical studies, we found that increased LAR on the day of ICU admission was associated with increased mortality in critically ill COVID-19 patients. Moreover, we found a statistically significant positive correlation between LAR with ICU admission SOFA score $(r=0.335, p<0.001)$ and APACHE-II score $(r=0.298, p<0.001)$. And, increased level of LAR on the day of ICU admission was associated with hemodynamic instability in critically ill COVID-19 patients. More importantly, with a cut-off value of 0.60 , LAR on the day of ICU admission is a significant and independent prognostic factor for the 30-day mortality in critically ill COVID-19 patients (HR:10.615 Cl:5.673-19.865, p<0.001). 


\section{CONCLUSION}

In conclusion, with a cutoff value of 0.60 , the lactate/albumin ratio on the day of ICU admission is an independent and significant predictor for the 30-days mortality in critically ill COVID-19 patients. Moreover, the mortality prediction performance of the LAR is superior to either serum lactate level or serum albumin level alone. Therefore, LAR can be a useful and easily reachable prognostic factor for early risk stratification of critically ill COVID-19 patients, and can help to manage critically ill COVID-19 patients better.

\section{TABLE LEGENDS}

Table 1. Baseline characteristics of the patients; survivors vs non-survivors

Table 2. Baseline laboratory parameters of the patients; survivors vs non-survivors

Table 3. The values of AUC, sensitivity and specificity of serum lactate level, serum albumin level and lactate albumin ratio for the prediction of 30-day mortality

Table 4.Comparison of the baseline clinical parameters of the patients; $L A R \leq 0.60$ vs $L A R>0.60$

Table 5. Comparison of the baseline laboratory parameters of the patients; $L A R \leq 0.60$ vs $L A R>0.60$

Table 6. Univariate survival analysis of the lactate, albumin, and lactate albumin ratio

Table 7. Multivariate Cox regression analysis of the lactate, albumin, and lactate albumin ratio

\section{FIGURE LEGENDS}

Figure 1. ROC analysis of $(A)$ lactate/albumin ratio $(B)$ serum lactate level $(C)$ serum albumin level for the predicting 30 -day mortality

Figure 2. Pearson correlation analysis of LAR with APACHE-II score and SOFA score

Figure 3. Kaplan-Meier 30-day survival curves for the critically ill COVID-19 patients by blood lactate level. P-values were calculated using the Log-rank test

Figure 4. Kaplan-Meier 30-day survival curves for the critically ill COVID-19 patients by lactate/albumin ratio. P-values were calculated using the Log-rank test 
Figure 5. Kaplan-Meier 30-day survival curves for the critically ill COVID-19 patients by serum albumin level. P-values were calculated using the Log-rank test

\section{REFERENCES}

1. Zhou F, Yu T, Du R, et al. Clinical course and risk factors for mortality of adult inpatients with COVID-19 in Wuhan, China: a retrospective cohort study. Lancet. 2020;395(10229):1054-1062.

2. Skegg D, Gluckman P, Boulton G, et al. Future scenarios for the COVID-19 pandemic. Lancet. 2021;397(10276):777-778.

3. Gao YD, Ding M, Dong X, et al. Risk factors for severe and critically ill COVID-19 patients: A review. Allergy. 2021;76(2):428-455.

4. Ye L, Chen B, Wang Y, et al. Prognostic value of liver biochemical parameters for COVID-19 mortality. Ann Hepatol. 2021;21:100279.

5. Gharipour A, Razavi R, Gharipour M, Modarres R, Nezafati P, Mirkheshti N. The incidence and outcome of severe hyperlactatemia in critically ill patients. Intern Emerg Med. $2021 ; 16(1): 115-123$.

6. Haas SA, Lange T, Saugel B, et al. Severe hyperlactatemia, lactate clearance and mortality in unselected critically ill patients. Intensive Care Med. 2016;42(2):202-210.

7. Lee SG, Song J, Park DW, et al. Prognostic value of lactate levels and lactate clearance in sepsis and septic shock with initial hyperlactatemia: A retrospective cohort study according to the Sepsis-3 definitions. Medicine (Baltimore). 2021;100(7):e24835.

8. Velavan TP, Kieu Linh LT, Kreidenweiss A, Gabor J, Krishna S, Kremsner PG. Longitudinal Monitoring of Lactate in Hospitalized and Ambulatory COVID-19 Patients. Am J Trop Med Hyg. 2021.

9. Kendall H, Abreu E, Cheng AL. Serum Albumin Trend Is a Predictor of Mortality in ICU Patients With Sepsis. Biol Res Nurs. 2019;21(3):237-244. 
10. Gharipour A, Razavi R, Gharipour M, Mukasa D. Lactate/albumin ratio: An early prognostic marker in critically ill patients. Am J Emerg Med. 2020;38(10):2088-2095.

11. Kasapoglu US, Arinc S, Gungor S, et al. Prognostic factors affecting survival in non-small cell lung carcinoma patients with malignant pleural effusions. Clin Respir J. 2016;10(6):791-799.

12. Akirov A, Masri-Iraqi H, Atamna A, Shimon I. Low Albumin Levels Are Associated with Mortality Risk in Hospitalized Patients. Am J Med. 2017;130(12):1465 e1411-1465 e1419.

13. Aziz M, Fatima R, Lee-Smith W, Assaly R. The association of low serum albumin level with severe COVID-19: a systematic review and meta-analysis. Crit Care. 2020;24(1):255.

14. Alhazzani W, Moller MH, Arabi YM, et al. Surviving Sepsis Campaign: guidelines on the management of critically ill adults with Coronavirus Disease 2019 (COVID-19). Intensive Care Med. 2020;46(5):854-887.

15. Huang J, Cheng A, Kumar R, et al. Hypoalbuminemia predicts the outcome of COVID-19 independent of age and co-morbidity. J Med Virol. 2020;92(10):2152-2158.

16. Violi F, Cangemi R, Romiti GF, et al. Is Albumin Predictor of Mortality in COVID-19? Antioxid Redox Signal. 2020.

17. Paliogiannis $P$, Mangoni AA, Cangemi M, Fois AG, Carru C, Zinellu A. Serum albumin concentrations are associated with disease severity and outcomes in coronavirus 19 disease (COVID-19): a systematic review and meta-analysis. Clin Exp Med. 2021.

18. Lichtenauer M, Wernly B, Ohnewein B, et al. The Lactate/Albumin Ratio: A Valuable Tool for Risk Stratification in Septic Patients Admitted to ICU. Int J Mol Sci. 2017;18(9).

19. Shin J, Hwang SY, Jo IJ, et al. Prognostic Value of The Lactate/Albumin Ratio for Predicting 28Day Mortality in Critically ILL Sepsis Patients. Shock. 2018;50(5):545-550.

20. Bou Chebl R, Jamali S, Sabra M, et al. Lactate/Albumin Ratio as a Predictor of In-Hospital Mortality in Septic Patients Presenting to the Emergency Department. Front Med (Lausanne). 2020;7:550182. 
21. Kong T, Chung SP, Lee HS, et al. The Prognostic Usefulness of the Lactate/Albumin Ratio for Predicting Clinical Outcomes in Out-of-Hospital Cardiac Arrest: a Prospective, Multicenter Observational Study (koCARC) Study. Shock. 2020;53(4):442-451.

22. Guo W, Zhao L, Zhao H, et al. The value of lactate/albumin ratio for predicting the clinical outcomes of critically ill patients with heart failure. Ann Transl Med. 2021;9(2):118.

23. Gallo Marin B, Aghagoli G, Lavine K, et al. Predictors of COVID-19 severity: A literature review. Rev Med Virol. 2021;31(1):1-10.

24. Ji P, Zhu J, Zhong Z, et al. Association of elevated inflammatory markers and severe COVID-19: A meta-analysis. Medicine (Baltimore). 2020;99(47):e23315.

25. Ferrando-Vivas P, Doidge J, Thomas K, et al. Prognostic Factors for 30-Day Mortality in Critically III Patients With Coronavirus Disease 2019: An Observational Cohort Study. Crit Care Med. 2021;49(1):102-111.

26. Gavin W, Campbell E, Zaidi SA, et al. Clinical characteristics, outcomes and prognosticators in adult patients hospitalized with COVID-19. Am J Infect Control. 2021;49(2):158-165.

27. Hu J, Wang Y. The Clinical Characteristics and Risk Factors of Severe COVID-19. Gerontology. 2021:1-12.

28. Peiro OM, Carrasquer A, Sanchez-Gimenez R, et al. Biomarkers and short-term prognosis in COVID-19. Biomarkers. 2021;26(2):119-126.

29. Huang W, Li C, Wang Z, et al. Decreased serum albumin level indicates poor prognosis of COVID-19 patients: hepatic injury analysis from 2,623 hospitalized cases. Sci China Life Sci. 2020;63(11):1678-1687.

30. Bassoli C, Oreni L, Ballone $\mathrm{E}$, et al. Role of serum albumin and proteinuria in patients with SARS-CoV-2 pneumonia. Int J Clin Pract. 2021;75(4):e13946.

31. Wang Z, Wang Z. Identification of risk factors for in-hospital death of COVID - 19 pneumonia -lessions from the early outbreak. BMC Infect Dis. 2021;21(1):113. 
32. Vassiliou AG, Jahaj E, llias I, et al. Lactate Kinetics Reflect Organ Dysfunction and Are Associated with Adverse Outcomes in Intensive Care Unit Patients with COVID-19 Pneumonia: Preliminary Results from a GREEK Single-Centre Study. Metabolites. 2020;10(10).

33. Wang B, Chen G, Cao Y, Xue J, Li J, Wu Y. Correlation of lactate/albumin ratio level to organ failure and mortality in severe sepsis and septic shock. J Crit Care. 2015;30(2):271-275. 


\begin{tabular}{|c|c|c|c|c|}
\hline & $\begin{array}{l}\text { Overall } \\
(n=282)\end{array}$ & $\begin{array}{c}\text { Survivors } \\
(n=145)\end{array}$ & $\begin{array}{l}\text { Non-survivors } \\
\quad(n=137)\end{array}$ & $P$ value \\
\hline Mean age, years $(\mathrm{Me} \pm \mathrm{SD})$ & $66.34 \pm 12.08$ & $63.60 \pm 12.89$ & $69.25 \pm 10.44$ & $<0.001^{*}$ \\
\hline $\begin{array}{l}\text { Age } \\
\geq 65 \text { years } \\
<65 \text { years }\end{array}$ & $\begin{array}{l}146(51.8 \%) \\
136(48.2 \%)\end{array}$ & $\begin{array}{l}61(42.1 \%) \\
84(57.9 \%)\end{array}$ & $\begin{array}{l}85(62 \%) \\
52(38 \%)\end{array}$ & $0.001^{* *}$ \\
\hline $\begin{array}{l}\text { Gender } \\
\text { Female } \\
\text { Male }\end{array}$ & $\begin{array}{l}103(36.5 \%) \\
179(63.5 \%)\end{array}$ & $\begin{array}{l}66(45.5 \%) \\
79(54.5 \%)\end{array}$ & $\begin{array}{l}37(27 \%) \\
100(73 \%)\end{array}$ & $0.001^{* *}$ \\
\hline $\begin{array}{l}\text { Comorbidities } \\
\text { Malignancy } \\
\text { CKD } \\
\text { Alzheimer disease } \\
\text { Cerebrovascular disease } \\
\text { Diabetes mellitus } \\
\text { COPD } \\
\text { Hypertension } \\
\text { CHF } \\
\text { CAD } \\
\text { Arrhythmia }\end{array}$ & $\begin{array}{c}4(1.4 \%) \\
14(5 \%) \\
24(8.5 \%) \\
7(8.5 \%) \\
108(38.3 \%) \\
62(22 \%) \\
192(68.1 \%) \\
37(13.1 \%) \\
88(31.2 \%) \\
23(8.2 \%)\end{array}$ & $\begin{array}{c}1(0.7 \%) \\
5(3.4 \%) \\
13(9.0 \%) \\
6(4.1 \%) \\
54(37.2 \%) \\
29(20.0 \%) \\
98(67.6 \%) \\
16(11.0 \%) \\
38(26.2 \%) \\
11(7.6 \%)\end{array}$ & $\begin{array}{c}3(2.2 \%) \\
9(6.6 \%) \\
11(8.0 \%) \\
1(0.7 \%) \\
54(39.4 \%) \\
33(24.1 \%) \\
94(68.6 \%) \\
21(15.3 \%) \\
50(36.5 \%) \\
12(8.8 \%)\end{array}$ & $\begin{array}{l}0.287^{\text {** }} \\
0.228^{* *} \\
0.778^{* \star} \\
0.066^{* \star} \\
0.707^{* *} \\
0.407^{* \star} \\
0.853^{* *} \\
0.286^{* \star} \\
0.062^{* *} \\
0.719^{* *}\end{array}$ \\
\hline SOFA score, (Min-Max) & $4.00(2-12)$ & $3.00(2-8)$ & $5.00(3-12)$ & $<0.001^{* * *}$ \\
\hline APACHE-II score, (Me $\pm S D)$ & $17.34 \pm 3.95$ & $15.65 \pm 3.21$ & $19.13 \pm 3.88$ & $<0.001^{*}$ \\
\hline $\begin{array}{l}\text { Invasive mechanical ventilation } \\
\text { support within the first } 24 \text { hours } \\
\text { Yes } \\
\text { No }\end{array}$ & $\begin{array}{c}41(14.5 \%) \\
241(85.5 \%)\end{array}$ & $\begin{array}{c}18(12.4 \%) \\
127(87.6 \%)\end{array}$ & $\begin{array}{l}23(16.7 \%) \\
114(83.3 \%)\end{array}$ & 0.298 \\
\hline $\begin{array}{l}\text { Use of vasoactive agent } \\
\text { Yes } \\
\text { No }\end{array}$ & $\begin{array}{l}139(49.3 \%) \\
143(50.7 \%)\end{array}$ & $\begin{array}{l}22(15.2 \%) \\
123(84.8 \%)\end{array}$ & $\begin{array}{l}117(85.4 \%) \\
20(14.6 \%)\end{array}$ & $<0.001^{* *}$ \\
\hline $\begin{array}{l}\text { Renal replacement therapy } \\
\text { Yes } \\
\text { No }\end{array}$ & $\begin{array}{c}19(6.7 \%) \\
263(93.3 \%)\end{array}$ & $\begin{array}{c}4(2.8 \%) \\
141(97.2 \%)\end{array}$ & $\begin{array}{c}15(10.9 \%) \\
122(89.1 \%)\end{array}$ & $0.006^{* \star}$ \\
\hline \multicolumn{5}{|c|}{$\begin{array}{l}\text { "Independent-samples T test } \\
{ }^{*} \text { Chi-squared test } \\
\text { CKD: chronic kidney disease, COPD: chronic obstructive pulmonary disease, CHF: chronic heart failure, CAD: } \\
\text { coronary artery disease, SOFA: Sequential Organ Failure Assessment, APACHE-II: Acute Physiology and Ch- } \\
\text { ronic Health Evaluation II, Min: minimum, Max: maximum, Me: mean, SD: standard deviation }\end{array}$} \\
\hline
\end{tabular}


Table 2. Baseline laboratory parameters of the patients; survivors vs non-survivors

\begin{tabular}{|c|c|c|c|c|}
\hline & & $\begin{array}{c}\text { Survivors } \\
(n=145)\end{array}$ & $\begin{array}{l}\text { Non-survivors } \\
\quad(n=137)\end{array}$ & $P$ value \\
\hline $\begin{array}{l}\text { Urea, mg/dL (Min-max) } \\
\text { Crea, mg/dL (Min-max) } \\
\text { AST, U/L (Min-max) } \\
\text { ALT, U/L (Min-max) } \\
\text { CK, U/L (Min-max) } \\
\text { LDH, IU/L (Mean } \pm S D) \\
\text { Albumin, g/dL (Mean } \pm S D)\end{array}$ & $\begin{array}{c}56.00(13-343) \\
0.88(0.36-12.02) \\
46.00(11-940) \\
34.00(5-850) \\
116.00(12-1000) \\
654.43 \pm 295.82 \\
2.85 \pm 0.44\end{array}$ & $\begin{array}{c}49.00(13-343) \\
0.81(0.36-9.00) \\
45.00(12-900) \\
33.00(5-404) \\
111.00(12-1000) \\
592.60 \pm 283.93 \\
2.95 \pm 0.47\end{array}$ & $\begin{array}{c}65.00(18-290) \\
0.99(0.50-12.02) \\
47.00(11-940) \\
35.00(6-850) \\
132.15(20-1000) \\
719.87 \pm 295.07 \\
2.73 \pm 0.39\end{array}$ & $\begin{array}{l}<0.001^{*} \\
<0.001^{*} \\
0.080^{*} \\
0.506^{*} \\
0.070^{*} \\
<0.001^{* *} \\
<0.001^{* *}\end{array}$ \\
\hline $\begin{array}{l}\text { Inflammatory parameters } \\
\text { Ferritin, ng/dL (Mean } \pm \text { SD) } \\
\text { CRP, mg/dL (Min-max) } \\
\text { PCT, ng/mL (Min-max) }\end{array}$ & $\begin{array}{c}891.00 \pm 619.48 \\
12.81(0.13-94.30) \\
0.25(0.02-50.56)\end{array}$ & $\begin{array}{c}745.33 \pm 561.99 \\
11.70(0.13-35.04) \\
0.19(0.02-4.38)\end{array}$ & $\begin{array}{c}1045.18 \pm 641.82 \\
13.64(1.08-94.30) \\
0.33(0.05-50.56)\end{array}$ & $\begin{array}{l}<0.001^{* *} \\
0.032^{*} \\
<0.001^{*}\end{array}$ \\
\hline 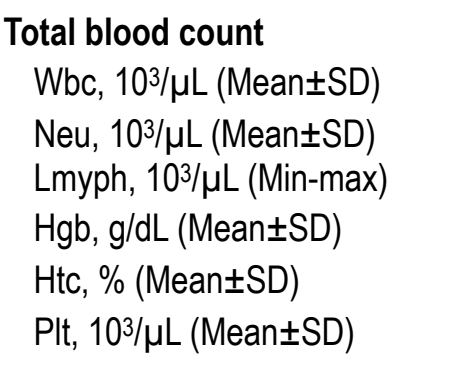 & $\begin{array}{c}12.48 \pm 6.25 \\
11.06 \pm 5.90 \\
0.70(0.11-5.67) \\
12.93 \pm 1.92 \\
39.15 \pm 5.88 \\
266.22 \pm 114.37\end{array}$ & $\begin{array}{c}11.92 \pm 6.29 \\
10.44 \pm 5.87 \\
0.75(0.20-5.67) \\
12.82 \pm 1.79 \\
38.93 \pm 5.52 \\
274.46 \pm 112.29\end{array}$ & $\begin{array}{c}13.07 \pm 6.18 \\
11.72 \pm 5.88 \\
0.64(0.11-2.83) \\
13.04 \pm 2.06 \\
39.38 \pm 6.25 \\
257.50 \pm 116.30\end{array}$ & $\begin{array}{l}0.123^{* *} \\
0.069^{* *} \\
0.001^{*} \\
0.325^{\star *} \\
0.519^{* *} \\
0.214^{* *}\end{array}$ \\
\hline $\begin{array}{l}\text { Cardiac markers } \\
\text { Trop-I, ng/mL (Min-max) } \\
\text { NT-proBNP, pg/mL (Min-max) }\end{array}$ & $\begin{array}{l}0.10(0.10-25.00) \\
1180(22-35000)\end{array}$ & $\begin{array}{c}0.10(0.01-25.00) \\
792(22-35000)\end{array}$ & & $\begin{array}{c}0.160^{*} \\
<0.001^{*}\end{array}$ \\
\hline $\begin{array}{l}\text { Coagulation parameters } \\
\text { INR, (Min-max) } \\
\text { Fibrinogen, ng/dL (Min-max) } \\
\text { D-Dimer, } \mu \mathrm{g} / \mathrm{mL} \text { (Min-max) }\end{array}$ & $\begin{array}{c}1.23(0.90-8.04) \\
488(50-1519) \\
1.68(0.01-39.20)\end{array}$ & $\begin{array}{c}1.21(0.90-3.92) \\
492(50-1477) \\
1.53(0.18-39.20\end{array}$ & & $\begin{array}{l}0.005^{*} \\
0.824^{*} \\
0.385^{*}\end{array}$ \\
\hline $\begin{array}{l}\text { Arterial blood gas analysis } \\
\mathrm{pH},(\text { Min-max) } \\
\mathrm{pO}_{2}, \mathrm{mmHg} \text { (Min-max) } \\
\mathrm{pCO}_{2}, \mathrm{mmHg} \text { (Min-max) } \\
\mathrm{HCO}_{3}, \mathrm{mEq} / \mathrm{L} \text { (Min-max) } \\
\left.\mathrm{SpO}_{2}, \% \text { (Mean } \pm \mathrm{SD}\right) \\
\text { Lactate, mmol/L (Min-max) }\end{array}$ & $\begin{array}{c}7.43(6.91-7.57) \\
61.75(35-227) \\
34.75(15-93) \\
22.93 \pm 4.80 \\
90.03 \pm 6.11 \\
2.00(0.50-12.20)\end{array}$ & $\begin{array}{c}7.44(6.91-7.57) \\
62.90(49-227) \\
35.20(15-93) \\
23.74 \pm 4.75 \\
91.59 \pm 4.26 \\
1.73 \pm 0.68\end{array}$ & $\begin{array}{c}7.42(7.10-7.56) \\
60.60(35-166) \\
34.40(17-81) \\
22.07 \pm 4.72 \\
88.37 \pm 7.25 \\
2.77 \pm 1.44\end{array}$ & $\begin{array}{c}0.002^{*} \\
0.009^{*} \\
0.742^{*} \\
0.003^{* *} \\
<0.001^{* *} \\
<0.001^{* *}\end{array}$ \\
\hline Lactate/albumin ratio & $0.68(0.18-4.36)$ & $0.55(0.18-2.50)$ & $0.92(0.34-4.36)$ & $<0.001^{*}$ \\
\hline \multicolumn{5}{|c|}{$\begin{array}{l}\text { "Mann-Whitney U Test } \\
\text { ** Independent-samples T test } \\
\text { Me: mean, SD: standard derivation, AST: aspartate aminotransferase, ALT: alanine aminotransferase, LDH: } \\
\text { lactate dehydrogenase, CK: creatine kinase, PCT: procalcitonin, NT-proBNP: N-terminal prohormone of brain } \\
\text { natriuretic peptide, CRP: C-reactive protein, Lymph: lymphocyte, Wbc: white blood cell, Neu: neutrophil, Hgb: } \\
\text { hemoglobin, Htc: hematocrit, PIt: platelets, INR: international normalized ratio, Trop-l: troponin-I, Crea: creatinin }\end{array}$} \\
\hline
\end{tabular}




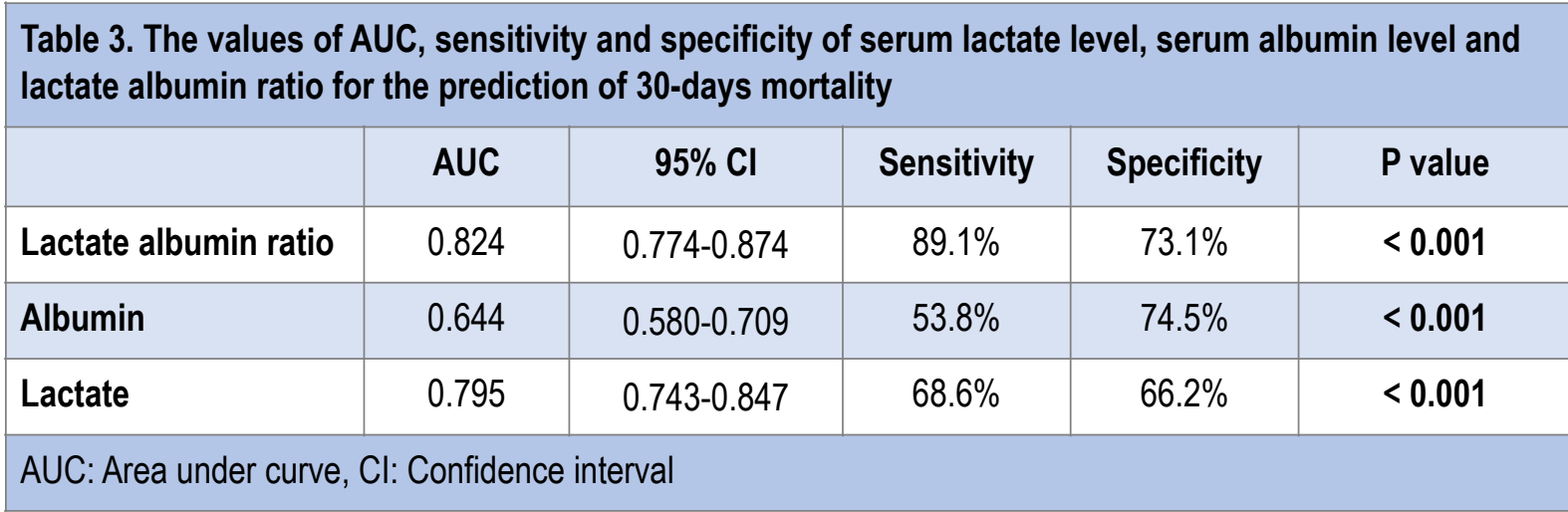




\begin{tabular}{|c|c|c|c|c|}
\hline & $\begin{array}{l}\text { Overall } \\
(n=282)\end{array}$ & $\begin{array}{c}\text { LAR } \leq 0.60 \\
(n=122)\end{array}$ & $\begin{array}{c}\text { LAR }>0.60 \\
(n=160)\end{array}$ & $P$ value \\
\hline Mean age, years $(\mathrm{Me} \pm \mathrm{SD})$ & $66.34 \pm 12.08$ & $63.76 \pm 13.09$ & $68.31 \pm 10.88$ & $<0.001^{*}$ \\
\hline $\begin{array}{l}\text { Age } \\
\geq 65 \text { years } \\
<65 \text { years }\end{array}$ & $\begin{array}{l}146(51.8 \%) \\
136(48.2 \%)\end{array}$ & $\begin{array}{l}52(42.6 \%) \\
70(57.4 \%)\end{array}$ & $\begin{array}{l}94(58.7 \%) \\
66(41.3 \%)\end{array}$ & $0.007^{* *}$ \\
\hline $\begin{array}{l}\text { Gender } \\
\text { Female } \\
\text { Male }\end{array}$ & $\begin{array}{l}103(36.5 \%) \\
179(63.5 \%)\end{array}$ & $\begin{array}{l}60(49.1 \%) \\
62(50.9 \%)\end{array}$ & $\begin{array}{c}43(26.8 \%) \\
117(73.2 \%)\end{array}$ & $<0.001^{* *}$ \\
\hline SOFA score, (Min-Max) & $4.00(2-12)$ & $3.00(2-12)$ & $5.00(2-11)$ & $<0.001^{*}$ \\
\hline APACHE-II score, (Me \pm SD) & $17.34 \pm 3.95$ & $16.17 \pm 3.55$ & $18.23 \pm 4.027$ & $<0.001^{*}$ \\
\hline $\begin{array}{l}\text { Invasive mechanical ventilation support } \\
\text { within the first } 24 \text { hours } \\
\text { Yes } \\
\text { No }\end{array}$ & $\begin{array}{c}41(14.5 \%) \\
241(85.5 \%)\end{array}$ & $\begin{array}{c}17(13.9 \%) \\
105(86.1 \%)\end{array}$ & $\begin{array}{c}24(15.0 \%) \\
136(85.0 \%)\end{array}$ & 0.801 \\
\hline $\begin{array}{l}\text { Use of vasoactive agent } \\
\text { Yes } \\
\text { No }\end{array}$ & $\begin{array}{c}81(28.8 \%) \\
201(71.2 \%)\end{array}$ & $\begin{array}{l}30(24.6 \%) \\
92(75.4 \%)\end{array}$ & $\begin{array}{c}51(31.8 \%) \\
109(68.2 \%)\end{array}$ & $<0.001^{* *}$ \\
\hline $\begin{array}{l}\text { Renal replacement therapy } \\
\text { Yes } \\
\text { No }\end{array}$ & $\begin{array}{c}19(6.7 \%) \\
263(93.3 \%)\end{array}$ & $\begin{array}{c}9(7.3 \%) \\
113(92.7 \%)\end{array}$ & $\begin{array}{c}10(6.2 \%) \\
150(93.8 \%)\end{array}$ & $0.708^{* *}$ \\
\hline $\begin{array}{l}\text { Survival status at day } 30 \\
\text { Alive } \\
\text { Deceased }\end{array}$ & $\begin{array}{l}145(51.4 \%) \\
137(48.6 \%)\end{array}$ & $\begin{array}{c}106(86.9 \%) \\
16(13.1 \%)\end{array}$ & $\begin{array}{c}39(24.4 \%) \\
121(75.6 \%)\end{array}$ & $<0.001$ \\
\hline \multicolumn{5}{|c|}{$\begin{array}{l}\text { "Independent-samples T test } \\
{ }^{* *} \text { Chi-squared test } \\
\text { SOFA: Sequential Organ Failure Assessment, APACHE-II: Acute Physiology and Chronic Health Evaluation II, } \\
\text { Min: minimum, Max: maximum, Me: mean, SD: standard deviation }\end{array}$} \\
\hline
\end{tabular}




\begin{tabular}{|c|c|c|c|c|}
\hline & $\begin{array}{l}\text { Overall } \\
(n=282)\end{array}$ & $\begin{array}{c}\text { LAR } \leq 0.60 \\
(n=122)\end{array}$ & $\begin{array}{l}\text { LAR }>0.60 \\
(n=160)\end{array}$ & $P$ value \\
\hline $\begin{array}{l}\text { Blood biochemical parameters } \\
\text { Urea, mg/dL (Min-max) } \\
\text { Crea, mg/dL (Min-max) } \\
\text { AST, U/L (Min-max) } \\
\text { ALT, U/L (Min-max) } \\
\text { CK, U/L (Min-max) } \\
\text { LDH, IU/L (Mean } \pm S D) \\
\text { Albumin, g/dL (Mean } \pm S D)\end{array}$ & $\begin{array}{c}56.00(13-343) \\
0.88(0.36-12.02) \\
46.00(11-940) \\
34.00(5-850) \\
116.00(12-1000) \\
654.43 \pm 295.82 \\
2.85 \pm 0.44\end{array}$ & $\begin{array}{c}51.00(13-343) \\
0.88(0.36-12.02) \\
43.50(14-900) \\
29.00(5-404) \\
116.35(12-1000) \\
594.05 \pm 279.49 \\
3.06 \pm 0.40\end{array}$ & $\begin{array}{c}61.50(18-226) \\
0.88(0.42-9.29) \\
49.00(11-940) \\
40.00(6-850) \\
116.00(20-1000) \\
700.47 \pm 300.47 \\
2.68 \pm 0.41\end{array}$ & 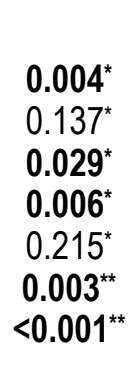 \\
\hline $\begin{array}{l}\text { Inflammatory parameters } \\
\text { Ferritin, ng/dL (Mean } \pm \text { SD) } \\
\text { CRP, mg/dL (Min-max) } \\
\text { PCT, ng/mL (Min-max) }\end{array}$ & $\begin{array}{c}891.00 \pm 619.48 \\
12.81(0.13-94.30) \\
0.25(0.02-50.56)\end{array}$ & $\begin{array}{c}688.94 \pm 553.08 \\
12.37(0.90-35.04) \\
0.19(0.02-11.67)\end{array}$ & $\begin{array}{c}1045.07 \pm 624.72 \\
13.09(0.13-94.30) \\
0.29(0.05-50.56)\end{array}$ & $\begin{array}{l}<0.001^{* *} \\
0.024^{*} \\
0.004^{*}\end{array}$ \\
\hline 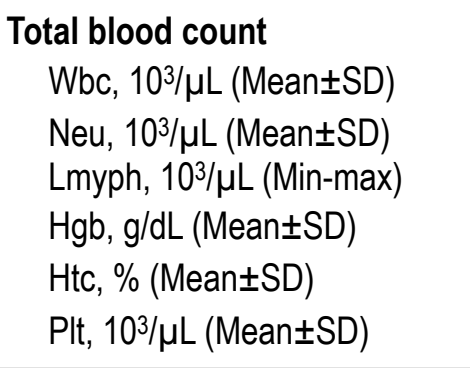 & $\begin{array}{c}12.48 \pm 6.25 \\
11.06 \pm 5.90 \\
0.70(0.11-5.67) \\
12.93 \pm 1.92 \\
39.15 \pm 5.88 \\
266.22 \pm 114.37\end{array}$ & $\begin{array}{c}11.01 \pm 5.73 \\
9.56 \pm 5.30 \\
0.75(0.20-5.20) \\
12.59 \pm 1.88 \\
38.39 \pm 6.12 \\
260.25 \pm 104.79\end{array}$ & $\begin{array}{c}13.61 \pm 6.24 \\
12.20 \pm 6.09 \\
0.65(0.11-5.67) \\
13.19 \pm 1.92 \\
39.73 \pm 5.65 \\
270.77 \pm 121.29\end{array}$ & $\begin{array}{l}<0.001^{* *} \\
<0.001^{* *} \\
0.036^{*} \\
0.100^{* *} \\
0.590^{* *} \\
0.445^{* *}\end{array}$ \\
\hline $\begin{array}{l}\text { Cardiac markers } \\
\text { Trop-I, ng/mL (Min-max) } \\
\text { NT-proBNP, pg/mL(Min-max) }\end{array}$ & $\begin{array}{l}0.10(0.10-25.00) \\
1180(22-35000)\end{array}$ & $\begin{array}{c}0.10(0.01-25.00) \\
792(22-35000)\end{array}$ & $\begin{array}{l}0.10(0.01-15.23) \\
1411(32-35000)\end{array}$ & $\begin{array}{l}0.167^{*} \\
0.001^{*}\end{array}$ \\
\hline $\begin{array}{l}\text { Coagulation parameters } \\
\text { INR, (Min-max) } \\
\text { Fibrinogen, ng/dL (Min-max) } \\
\text { D-Dimer, } \mu \text { g/mL (Min-max) }\end{array}$ & $\begin{array}{c}1.23(0.90-8.04) \\
488(50-1519) \\
1.68(0.01-39.20)\end{array}$ & $\begin{array}{c}1.21(0.90-11.67) \\
493(189-1477) \\
1.24(0.10-39.20)\end{array}$ & $\begin{array}{c}1.25(0.98-8.04) \\
481(50-1519) \\
2.00(0.01-35.50)\end{array}$ & $\begin{array}{l}0.006^{*} \\
0.899^{*} \\
0.001^{*}\end{array}$ \\
\hline $\begin{array}{l}\text { Arterial blood gas analysis } \\
\mathrm{pH},(\mathrm{Min}-\mathrm{max}) \\
\mathrm{pO}_{2}, \mathrm{mmHg} \text { (Min-max) } \\
\mathrm{pCO}_{2}, \mathrm{mmHg} \text { (Min-max) } \\
\mathrm{HCO}_{3}, \mathrm{mEq} / \mathrm{L} \text { (Min-max) } \\
\left.\mathrm{SpO}_{2} \% \text { (Mean } \pm \mathrm{SD}\right) \\
\text { Lactate,mmol/L(Min-max) }\end{array}$ & $\begin{array}{c}7.43(6.91-7.57) \\
61.75(35-227) \\
34.75(15-93) \\
22.93 \pm 4.80 \\
90.03 \pm 6.11 \\
2.00(0.50-12.20)\end{array}$ & $\begin{array}{c}7.43(6.91-7.57) \\
64.60(49-227) \\
35.00(15-93) \\
23.07 \pm 5.47 \\
91.88 \pm 4.19 \\
1.50(0.50-2.20)\end{array}$ & $\begin{array}{c}7.43(7.10-7.56) \\
60.00(35-166) \\
34.40(17-81) \\
22.81 \pm 4.24 \\
88.62 \pm 6.93 \\
2.50(1.50-12.20)\end{array}$ & $\begin{array}{l}0.375^{*} \\
0.001^{*} \\
0.810^{*} \\
0.395^{* *} \\
<0.001^{* *} \\
<0.001^{*}\end{array}$ \\
\hline \multicolumn{5}{|c|}{$\begin{array}{l}\text { * Mann-Whitney U Test } \\
\text { ** Independent-samples T test } \\
\text { Me: mean, SD: standard deviation, AST: aspartate aminotransferase, ALT: alanine aminotransferase, LDH: lac- } \\
\text { tate dehydrogenase, CK: creatine kinase, PCT: procalcitonin, NT-proBNP: N-terminal prohormone of brain nat- } \\
\text { riuretic peptide, CRP: C-reactive protein, Lymph: lymphocyte, Wbc: white blood cell, Neu: neutrophil, Hgb: he- } \\
\text { moglobin, Htc: hematocrit, PIt: platelets, INR: international normalized ratio, Trop-I: troponin-I, Crea: creatinin }\end{array}$} \\
\hline
\end{tabular}




\begin{tabular}{|c|c|c|c|c|c|}
\hline & \multirow[b]{2}{*}{ Number of patients } & \multirow{2}{*}{$\begin{array}{l}\text { Mean survival } \\
\text { time (days } \pm S E \text { ) }\end{array}$} & \multicolumn{2}{|c|}{$95 \% \mathrm{Cl}$} & \multirow[b]{2}{*}{ P-value* } \\
\hline & & & Lower bound & $\begin{array}{l}\text { Upper bo- } \\
\text { und }\end{array}$ & \\
\hline $\begin{array}{l}\text { Blood lactate level } \\
\quad>2 \mathrm{mmol} / \mathrm{L} \\
\quad \leq 2 \mathrm{mmol} / \mathrm{L}\end{array}$ & $\begin{array}{l}135(47.9 \%) \\
147(52.1 \%)\end{array}$ & $\begin{array}{l}17.14 \pm 0.86 \\
24.57 \pm 0.71\end{array}$ & $\begin{array}{l}15.46 \\
23.16\end{array}$ & $\begin{array}{l}18.83 \\
25.97\end{array}$ & $<0.001$ \\
\hline $\begin{array}{l}\text { Serum albumin level } \\
\quad<3.5 \mathrm{mg} / \mathrm{dL} \\
\quad \geq 3.5 \mathrm{mg} / \mathrm{dL}\end{array}$ & $\begin{array}{l}169(59.9 \%) \\
113(40.1 \%)\end{array}$ & $\begin{array}{l}19.02 \pm 0.76 \\
24.00 \pm 0.88\end{array}$ & $\begin{array}{l}17.52 \\
22.27\end{array}$ & $\begin{array}{l}20.52 \\
25.72\end{array}$ & $<0.001$ \\
\hline $\begin{array}{l}\text { Lactate albumin ratio } \\
\qquad 0.6 \\
\quad>0.6\end{array}$ & $\begin{array}{l}122(43.3 \%) \\
160(56.7 \%)\end{array}$ & $\begin{array}{l}27.86 \pm 0.52 \\
15.79 \pm 0.74\end{array}$ & $\begin{array}{l}26.83 \\
14.33\end{array}$ & $\begin{array}{l}28.90 \\
17.25\end{array}$ & $<0.001$ \\
\hline
\end{tabular}


Table 7. Multivariate Cox regression analysis of the lactate, albumin, and lactate albumin ratio on 30 day survival time

\begin{tabular}{|l|c|c|c|c|}
\hline & \multirow{2}{*}{ Hazard ratio } & \multicolumn{2}{|c|}{$95 \% \mathrm{Cl}$} & \multirow{2}{*}{ P-value $^{*}$} \\
\cline { 3 - 4 } & & Lower bound & Upper bound & \\
\hline Hyperlactatemia & 0.828 & 0.548 & 1.252 & 0.372 \\
\hline Hypoalbuminemia & 0.859 & 0.572 & 1.289 & 0.463 \\
\hline Increased lactate albumin ratio & 10.615 & 5.673 & 19.865 & $<0.001$ \\
\hline Cl: confidence interval & & & & \\
\hline
\end{tabular}


Figures
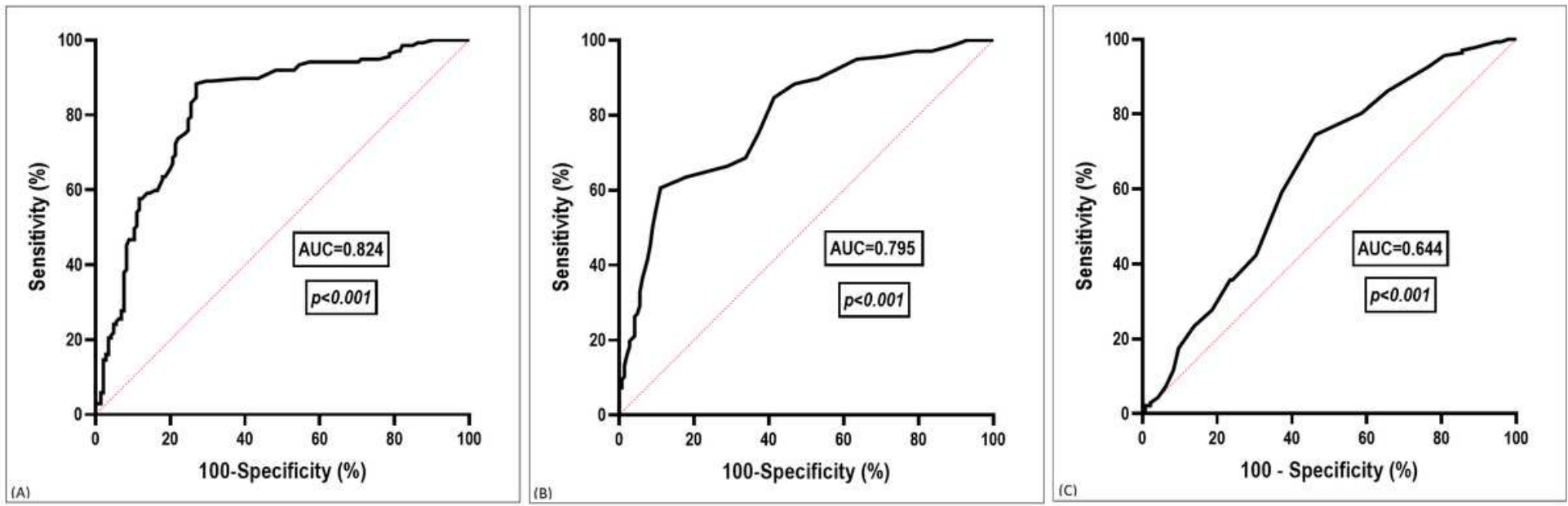

Figure 1

ROC analysis of (A) lactate/albumin ratio (B) serum lactate level (C) serum albumin level for the predicting 30-day mortality
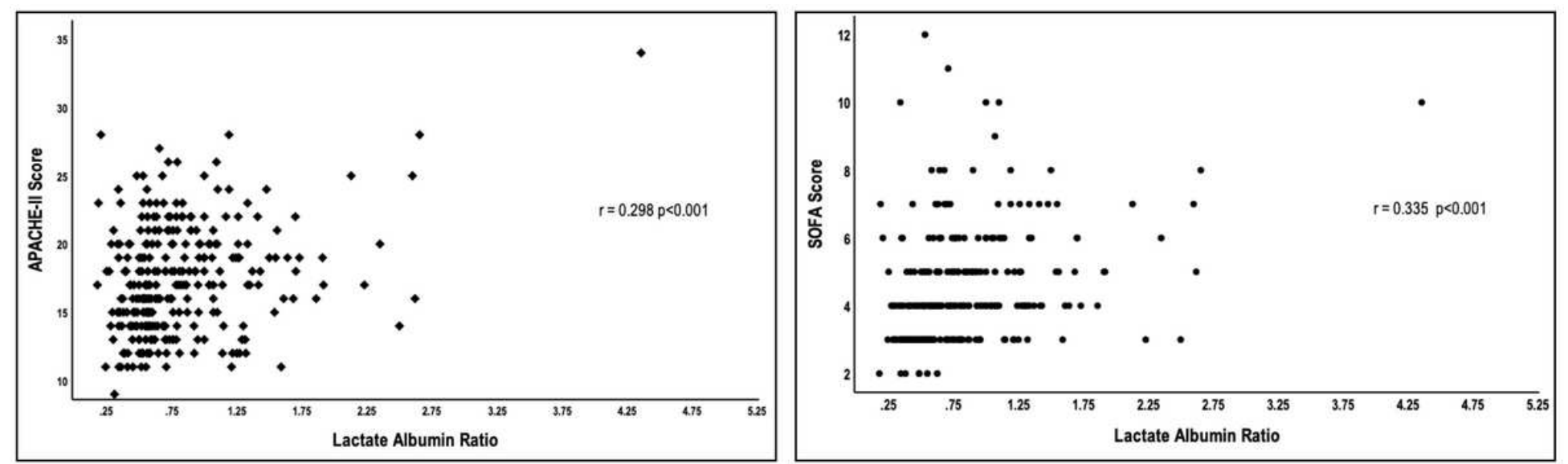

Figure 2

Pearson correlation analysis of LAR with APACHE-II score and SOFA score 


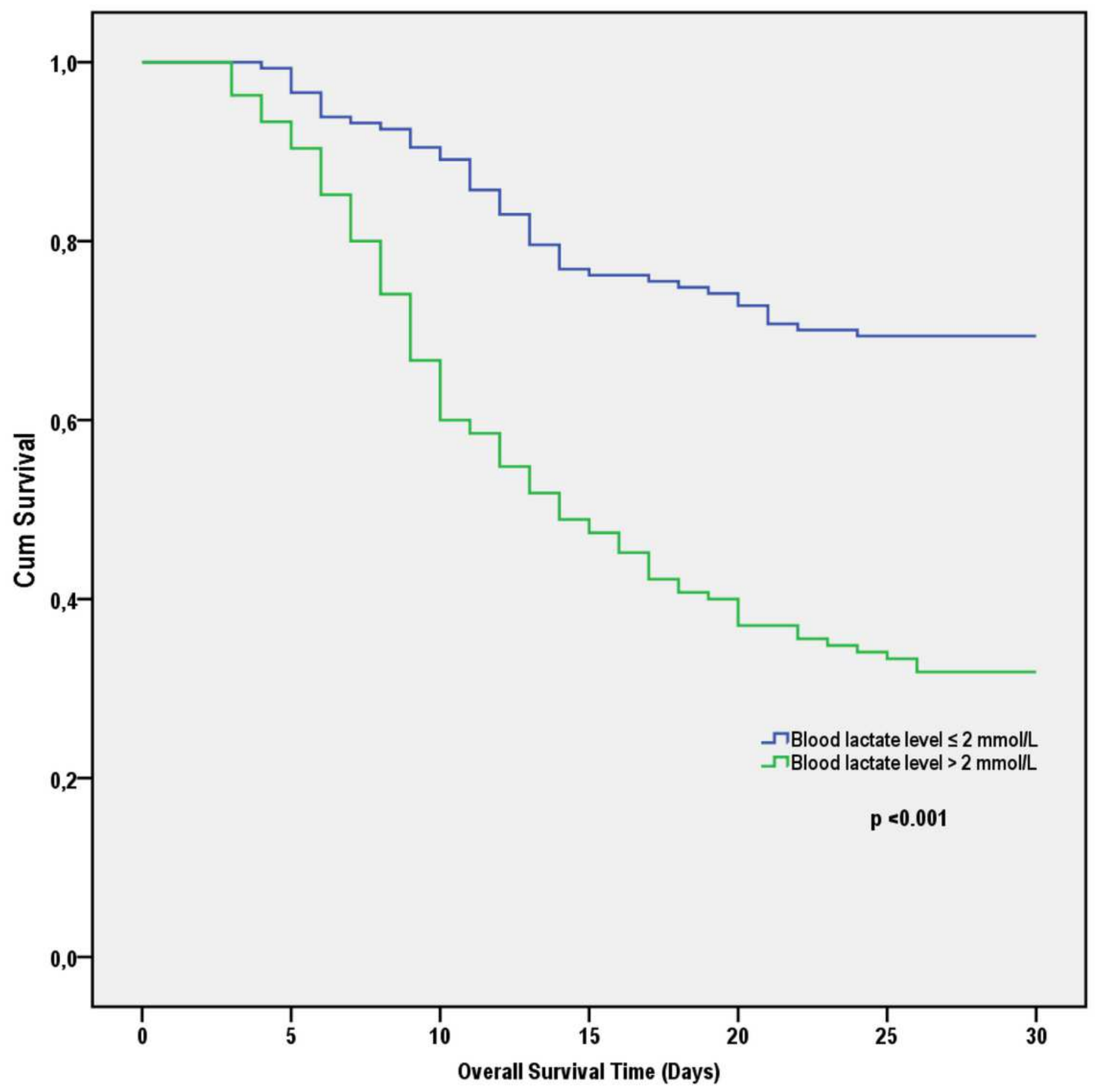

Figure 3

Kaplan-Meier 30-day survival curves for the critically ill COVID-19 patients by blood lactate level. Pvalues were calculated using the Log-rank test 


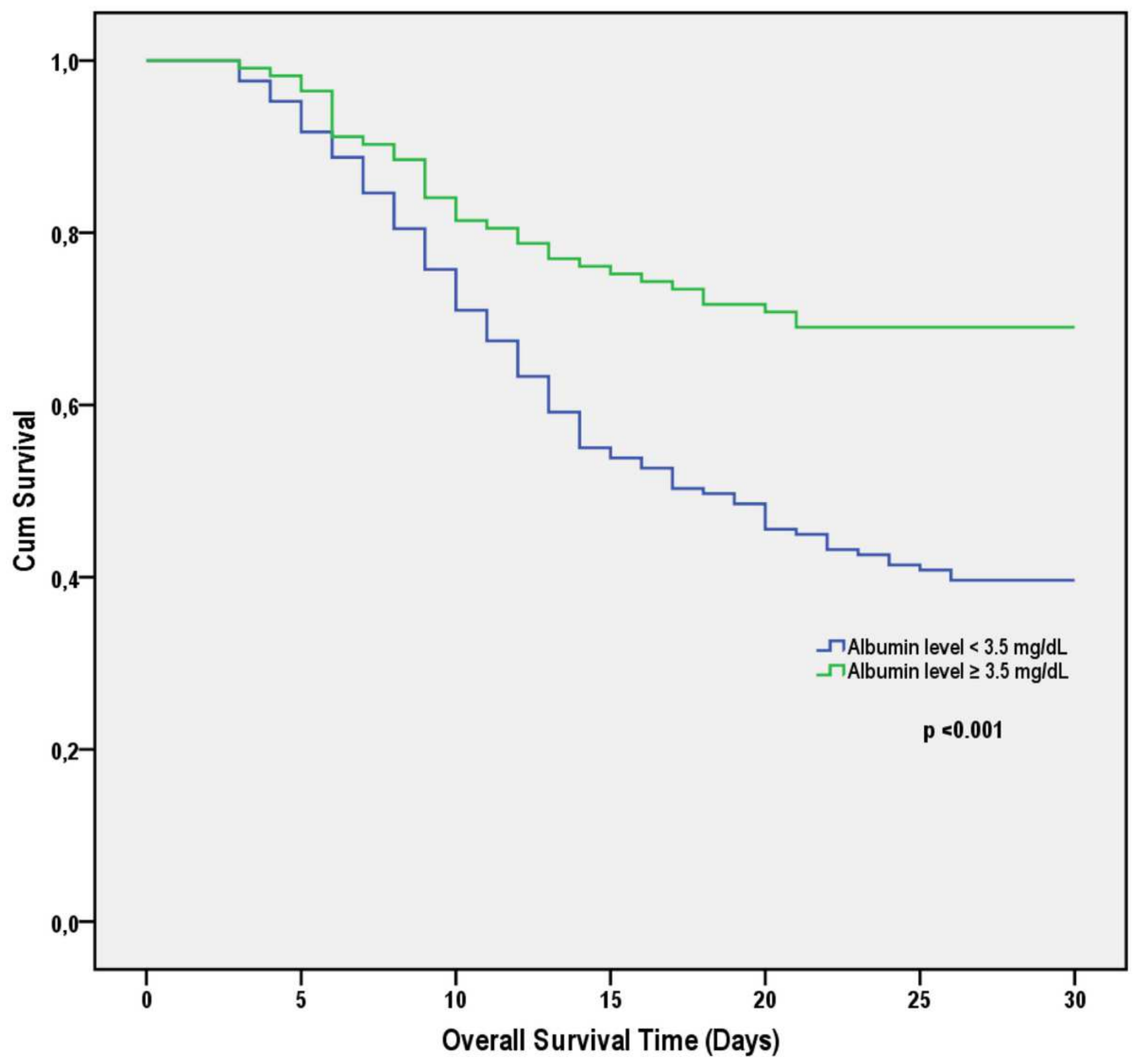

Figure 4

Kaplan-Meier 30-day survival curves for the critically ill COVID-19 patients by lactate/albumin ratio. Pvalues were calculated using the Log-rank test 


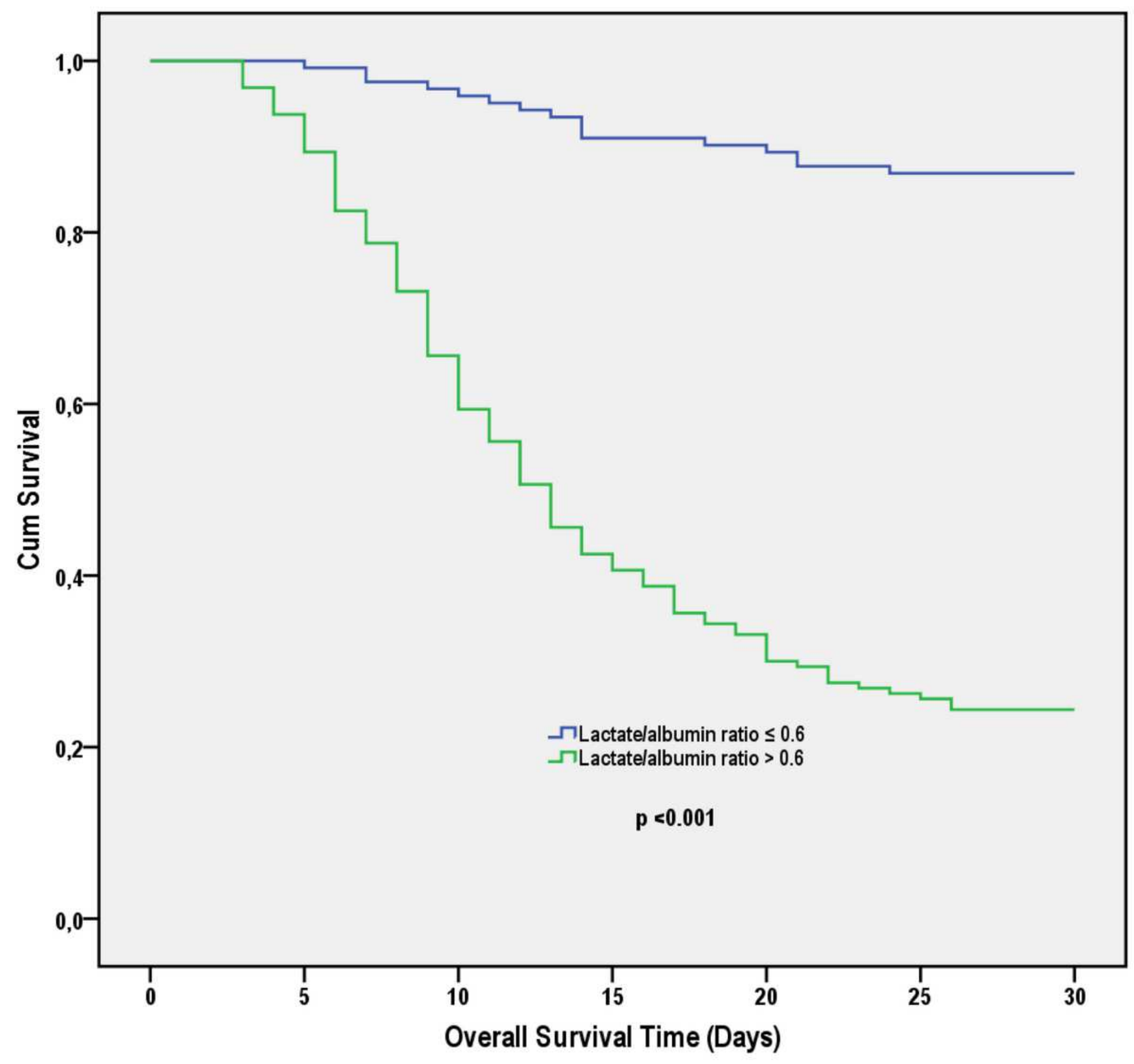

Figure 5

Kaplan-Meier 30-day survival curves for the critically ill COVID-19 patients by serum albumin level. Pvalues were calculated using the Log-rank test 